\title{
HPV Induced Oropharyngeal Carcinoma - A critical review
}

\author{
Hephzibah $\mathrm{G}^{1}$, Nandan SRK${ }^{2}$, Pavan G Kulkarni ${ }^{3}$, Shyam Prasad Reddy $\mathrm{D}^{4}$
}

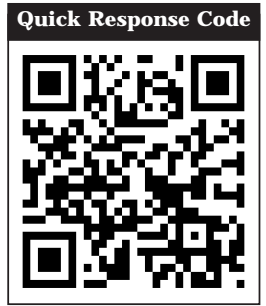

doi: $10.5866 / 2017.9 .10035$

${ }^{1}$ Post graduate student

${ }^{2}$ Professor \& HOD

${ }^{3} \& 4$ Reader

Department of Oral and maxillofacial pathology

Kamineni Institute of Dental Sciences,

Narketpally, Nalgonda, Telangana.

\section{Article Info:}

Received: J anuary 8, 2017

Review Completed: February 7, 2017

Accepted: March 9, 2017

Available Online: March, 2017 (www.nacd.in)

(c) NAD, 2017 - All rights reserved

Email for correspondence:

drhephzibah.kids@gmail.com

\begin{abstract}
:
Oral cancer is the most frequent cancer of the head and neck region and is one of the common causes of mortality. The effect of etiological factors such as tobacco and alcohol consumption in its causation is well known, however there are a growing number of cancers that occur in patients without exposure to these established factors and a viral association especially human papilloma virus has been referred to the development of oral cancer in such patients. Human papilloma virus, a DNA virus has been implicated as an etiological agent for a subset of oral squamous cell carcinomas especially those arising from the oropharynx. Human papilloma virus associated tumors are a distinct dinico pathol ogic entity and they havea better prognosis as compared to the human papilloma virus negative carcinomas. It is thereforeimportant to assess oral cancer in patients without the potential risk factors, focusing on the role of human papilloma virus enabling to improve the diagnosis and an appropriate clinical management.
\end{abstract}

Key words: Oropharyngeal carcinoma, Human papilloma virus, oncoproteins

\section{INTRODUCTION:}

The word cancer is derived from the Greek terminology "Karkinos" which means crab and it denotes how carcinoma extends its claws like a crab into the adjacent tissues. ${ }^{1}$ Oral cancer denotes the malignancy arising from the oral tissues and oral squamous cell carcinoma is the $6^{\text {th }}$ most common cancer worldwide. ${ }^{2,3}$ It represents the most frequent cancer of the head and neck region, with squamous cell carcinoma being the most common entity accounting for almost 90 - 95\% of all malignancies of the oral cavity. ${ }^{4}$ Several factors like age, gender, genetic background, lifestyle, status of health and exposure to one or more oncogenic factors are said to be involved in oral carcinogenesis and tobacco smoking and alcohol consumption are well established etiological factors for oral cancer. ${ }^{5}$ However, there are a considerable number of younger patients who inspite of not being extensively exposed to these established etiological factors devel op oral cancer. The role of thesefactors in these patients is not certain due to the short time of exposure and the etiology of oral squamous cell carcinoma in such individuals is unclear. ${ }^{6,7} \mathrm{~A}$ viral association has been referred to the development of oral squamous cell carcinoma in this group and high 
risk human papilloma virus (HPV) infection has been documented to play a role in carcinogenesis in such patients. ${ }^{7,8}$ HPV induced squamous cell carcinoma more frequently develops from the oropharyngeal region and the oropharynx is the head and neck site that has a definite etiological association between persistent HPV infection and the development of squamous cell carcinoma. HPV positive malignancies represent about $40-90 \%$ of malignancies arising from the oropharynx. ThereforeHPV associated oropharyngeal squamous cell carcinoma (OPSCC) now represents a significantly higher proportion of head and neck squamous cell carcinoma and is a distinct clinical and molecular entity. ${ }^{9}$

\section{Structure and Life Cycle of HPV :}

HPV is a non envel oped DNA virus belonging to the Papillomaviridae family having a diameter of 52 $55 \mathrm{~nm}$ and covered by an icosahedral capsid composed of 72 capsomers. ${ }^{10}$ The HPV genome has about 7200 - 8200 base pairs and molecular biology techniques have characterized the HPV genome. It has 8 open reading frames, divided into three functional regions. The first region is the Early (E) region which codes for early functional proteins and extends for about $45 \%$ of the genome. The second region is the Late $(L)$ region which codes for late structural proteins and extends for about $40 \%$ of the genome. The third region is the Long control region (LCR), its sequences regulate genetranscription and performs regulatory functions. ${ }^{11}$

HPVs possess a special tropism for squamous epithelial cells and the life cycle of HPV begins with infection of stem cells in the basal layer of the epithelium. After entry into the cells, the virus expresses $E 1$ and $E 2$ genes. These proteins bind to the viral origin of replication and recruit DNA polymerases and other proteins required for replication of DNA. In the suprabasal layer, there will be expression of the genes E1, E2, E5, E6 and $\mathrm{E} 7$ and these contribute to maintaining the viral genome and induce cell proliferation, thus resulting in a higher number of cells that produce infectious virions. In the granular layer, the products of the genes $L 1$ and $L 2$ and the major and minor proteins of the viral capsid gather and assemble the viral capsids, which reach the cornified layer of the epithelium and are released. ${ }^{12}$

Till date, more than 130 genotypes of HPV have been identified and they are categorized based on their oncogenic potential as low risk (HPV-6, 11, 13, 32) and high risk types (HPV-16, 18, 31, 33, 35). ${ }^{13}$ Low risk genotypes of HPV have been associated with benign oral proliferative epithelial lesions, while high risk genotypes have been associated with potentially malignant and malignant oral epithelial lesions and HPV 16 and 18 are the high risk HPV genotypes that are most frequently detected in malignant oral epithelial lesions. ${ }^{13,}{ }^{14}$ In benign lesions, the virus is not integrated into the genome of the host cell, where as it is integrated into the genome of the host cell in case of malignant lesions. ${ }^{15}$

\section{Pathogenesis of H PV Induced Carcinogenesis:}

Syrjanen first proposed the involvement of HPV in oral and oropharyngeal carcinoma and its involvement was based on the following elements: the specificity of HPV to epithelial cells, the oncogenic potential of HPV in the pathogenesis of cervical sqamous cell carcinoma and the morphological similarity between oropharyngeal and genital epithelia.7,8

The oncogenic potential of high risk genotypes of HPV is attributed to the integration of the virus into the host genome. ${ }^{15}$ During this process of integration, the circular form of viral genome breaks at the level of $E 1$ and $E 2$ regions and the $E 2$ open reading frame has been found to be the preferred site of viral integration as it has been deleted or disrupted more frequently than other sites. ${ }^{15,16}$ The loss of these regions produces loss of control of E 6 and $E 7$ leading to enhanced expression of these two viral oncogenes. The E 6 and E 7 viral oncoproteins are normally controlled by the E2 and E1 inhibitory genes and upon integration these genes are altered or deleted, leading to unchecked transcription of these viral oncoproteins. ${ }^{15-17}$ The E 6 and E 7 oncoproteins then inactivate the tumour suppressors - p53 and Retinoblastoma $(\mathrm{Rb})$ and the carcinogenic effect of high risk HPVs has been attributed to a large extent to these two viral gene products. ${ }^{9,18}$

The E 6 viral oncoprotein causes degradation of p53 and substantial loss of its activity via the ubiquitin pathway. E6 binds to E6AP, a cellular protein and the resulting complex between E6 and E6AP is responsible for ubiquitination and subsequent degradation of p53. As a consequence, the normal functions of p53 such as cell cyclearrest or induction of apoptosis are hampered resulting in a higher susceptibility to genomic instability. The carcinogenic effect of E 7 is attributed to its ability 
of causing degradation and inactivation of $\mathrm{pRb}$, thus preventing the binding of $\mathrm{pRb}$ to the transcription factor E2F, which is required for progression of the cell cycle. ${ }^{19}$ Consequently, there is release of E $2 F$ with promotion of the G1-S phase transition of the cell cycle and transcription of genes required for progression of the cell cycle.

Persistent expression of the viral oncoproteins E6 and E 7 leads to activation of protooncogenes, resulting in the fully malignant phenotype. ${ }^{9}$ F urther, the carcinogenic effect of tobacco, alcohol and other carcinogens may be increased by HPV infection and neovascularisation and cellular immortality arealso said to be associated with HPV infection.

Normally $\mathrm{pRb}$ functions as a negative regulator of p16, which is a tumor suppressor protein located on chromosome 9p21 that inhibits the cyclin D - CDK4 complex, thereby preventing phosphorylation of $\mathrm{pRb}$ and inhibition of cell cycle progression. ${ }^{20}$ As the E 7 viral oncoprotein causes inactivation of pRb, p16 is released from its negative feedback control, causing an increase in the levels of p16. ${ }^{21}$ As a consequence, there is overexpression of p16 in the nucleus and cytoplasm of tumor cells affected by HPV which can be visualized immunohistochemically and is thus consi dered as an indirect marker of HPV infection. ${ }^{22}$

\section{Clinical Features:}

HPV s are mostly transmitted by sexual contact but it can also be acquired through vertical spread and self inoculation. ${ }^{11}$ It may infect the keratinized surface of the skin or thelining of the mouth, throat, respiratory or anogenital tract epithelium based on which they are characterized as cutaneous types or mucosal types accordingly. ${ }^{12}$ The HPVs that infect the mucosal epithelium have been categorized as low risk or high risk types based on their oncogenic potential and association with carcinoma of the cervix. ${ }^{14}$ The low risk HPVs have a low oncogenic potential as they have a low affinity for tumor suppressor proteins and they are thus associated with benign lesions. ${ }^{23}$ The lesions usually regress spontaneously in the immunocompetent individuals while they persist in immunodeficient individuals. Persistent infection with HPV and integration of the viral genome into the host genome contribute to increasing the risk of malignancy. ${ }^{12}$

HPV positive squamous cell carcinomas are more likely to arise in middle aged white men and in individuals with an increased number of sexual partners and a history of marijuana use. They are less likely to arise in individuals with heavy tobacco and alcohol exposure. ${ }^{24}$ The presence of HPV infection is more frequent in the oropharyngeal region probably due to the invading crypts that provide a large epithelial surface and the non keratinised mucosa that facilitate access of the virus to the basal cells. ${ }^{6}$ The palatine tonsils and base of the tongue are more commonly involved than other oropharyngeal subsites and this may be attributed to the reticulated epithelium covering the tonsillar crypts having epithelial disruptions, that render the basement membrane unprotected against viral deposition thus making it more prone to HPV infection. ${ }^{9}$

HPV associated malignancies are a distinct clinicopathologic entity that present usually with smaller primary tumors, have fewer gross chromosomal aberrations and thus have a better prognosis in comparison to the non HPV associated tumors. ${ }^{10,25}$

There is a large variation in HPV prevalence in different parts of the world ranging from 19 to $72 \%$ and the prevalence of high risk HPV in oro pharyngeal cancer has been reported to be highest in North America. ${ }^{24,}{ }^{26}$ This great variation in HPV prevalence may be due to differences between the populations analysed, differences in the methods for extraction of DNA, the samples used for testing and most importantly the HPV detection methods used. ${ }^{27}$

\section{Detection of HPV:}

Although there has been a decline in the overall incidence of head and neck squamous cell carcinoma, there has been a rise in the incidence of squamous cell carcinoma of the oropharyngeal sites in which HPV positive tumors predominate. Therefore, identification of the HPV status in OPSCC has become important in clinical practice. ${ }^{28}$

HPV cannot be cultured in vitro, therefore its detection is done through analysis of HPV DNA sequence using nucleic acid probes and detection of HPV DNA is the most widely used method to diagnose HPV infection. The various methods for detection of HPV DNA include direct nucleic acid probe methods like insitu hybridization (ISH) and Southern blot, target amplification methods most notably Polymerase chain reaction( PCR) and hybridization signal amplification which is an extension of direct probe techniques. Target amplification is said to be the most sensitive of all DNA analysis techniques and PCR has been recognized as the most appropriate method to 
identify HPV because of its higher sensitivity and specificity. ${ }^{29}$

PCR based detection of HPV E6 mRNA in frozen sections is considered to be the most appropriate method for the detection of oncologically relevant HPV infection. However, this method is not feasible in routine pathology laboratories and there are difficulties with analysis of mRNA from paraffin embedded mucosal biopsies also because of degradation of RNA and mixture of mRNA from lesional and non lesional tissues. ${ }^{9,} 30$ Moreover, HPV specific PCR is not routinely available in most diagnostic laboratories and traditional PCR may be too sensitive, amplifying contaminant HPV from the laboratory environment or other specimens rather than from a tumor in which the virus is present. In situ hybridization allows direct visualization of the virus in tumor cells and is quite specific for high risk HPV and is also more practical in a clinical setting. However, reactivity can be very focal, nonspecific staining is common and it is not completely sensitive. Therefore, the best method for HPV detection remains controversial. ${ }^{28}$

A frequently recommended approach is to use a combination of p16 immunohistochemistry followed by ISH and immunohistochemical detection of p16 is often used as an indirect marker for HPV infection along with HPV diagnostics. ${ }^{28,}{ }^{31}$ p16 is a tumor suppressor protein that inhibits cyclin dependant kinases and immunohistochemical staining of p16 can be used as an alternative method to indicate the expression of E7 viral oncoprotein through a mechanism in which E 7 inactivates $p R b$ and releases the negative feedback inhibition on p16 expression. ${ }^{28,} 30$ Immunohistochemical detection of p16 is generally accessible and it has a lower cost than other HPV specific tests. ${ }^{32}$ This approach is very practical and can detect HPV in a high percentage of OPSCC. ${ }^{33}$

\section{Treatment and Prognosis:}

The treatment of patients with HPV positivetumors will essentially be the same treatment as that of patients with HPV negative tumors and is based on the stage of the disease and the general health condition of the patient. ${ }^{9}$ These tumors have favorable clinical outcomes as they respond well to all standard treatments whether they be surgery, radiotherapy, chemotherapy or combined modality therapy. ${ }^{28}$ However, aggressive multimodality therapies would not be appropriate for HPV positive patients who are younger and have a prolonged survival as significant toxicities are associated with current treatment regimens used in clinical practice and patients must live with these adversetreatment related effects for longer periods of time. ${ }^{9,} 33$ In this context, clinical trials have been developed towards a de-intensified therapy with the intent to reduce toxicity and substantial morbidity associated with cancer treatments while maintaining clinical efficacy, thereby improving the long term quality of life. $^{9}$

HPV associated tumors havea better prognosis than the non HPV associated tumors as they have a lower risk of tumor progression and an enhanced sensitivity to ionizing radiation. ${ }^{34}$ In a recent meta analysis, it was reported that patients with HPV positive oropharyngeal and head and neck squamous cell carcinomas wereless likely to experience cancer recurrence than patients with HPV negative tumors. Furthermore, patients with HPV positive tumors had a $50 \%$ reduction in overall mortality compared with the HPV negative patients. The favourable outcome and better prognosis of HPV induced squamous cell carcinomas may be attributed to an enhanced sensitivity to treatment due to a wild type p53, allowing an apoptotic response of tumor cells to radiation and chemotherapy. ${ }^{9}$

\section{References:}

1. George A, Sreenivasan BS, Sunil S, Varghese SS, Thomas J , Gopakumar D, Mani V. Potentially malignant disorders of oral cavity. J Oral Maxillofac Pathol 2011; 2(1):95-100.

2. Tsantoulis PK, Kastrinakis NG, Tourvas AD, Laskaris G, Gorgoulis VG. Advances in the biology of oral cancer. Oral Oncol 2007; 43(6):523-34.

3. Negi A, Puri A, Gupta R, Nangia R, Sachdeva A, Mittal M. Comparison of immunohistochemical expression of antiapoptotic protein survivin in normal oral mucosa, oral leukoplakia, and oral squamous cell carcinoma. Pathology research international. 2015.

4. Don KR, Ramani P, Ramshankar V, Sherlin HJ , Premkumar $\mathrm{P}$, Natesan A. Promoter hypermethylation patterns of P16, DAPK and MGMT in oral squamous cell carcinoma: $A$ systematic review and meta-analysis. Indian J Dent Res 2014; 25(6):797-805.

5. Pannone G, Santoro A, Papagerakis S, Muzio LL, De Rosa $G$, Bufo $P$. The role of human papillomavirus in the pathogenesis of head \& neck squamous cell carcinoma: an overview. Infect Agent Cancer 2011; 6(4):1-11.

6. Kaminagakura E, Villa LL, Andreoli MA, Sobrinho J S, Vartanian J G, Soares FA, Nishimoto IN, Rocha R, Kowalski LP. Highrisk human papillomavirus in oral squamous cell carcinoma of young patients. Int J Cancer 2012; 130(8):172632. 
7. Vargas-Ferreira F, Nedel F, Etges A, Gomes AP, Furuse C, TarquinioSB. Etiologic factors associated with oral squamous cell carcinoma in non-smokers and non-alcoholic drinkers: a brief approach. Braz Dent J 2012; 23(5):586-90.

8. Khangura RK, Sengupta S, Sircar K, Sharma B, Singh S, Rastogi V. HPV involvement in OSCC: Correlation of PCR results with light microscopic features. J Oral Maxillofac Pathol 2013; 17(2):195-99.

9. Boscolo-Rizzo P, Del Mistro A, Bussu FR, Lupato V, Baboci L, Almadori G, Da Mosto MC, Paludetti GA. New insights into human papillomavirus-associated head and neck squamous cell carcinoma. Acta Otorhinolaryngol ogica I talica 2013; 33:77-87.

10. Ajila V, Shetty H, Babu S, Shetty V, Hegde S. Human Papilloma Virus Associated Squamous Cell Carcinoma of the Head and Neck. J ournal of sexually transmitted diseases 2015:1-5.

11. Fede D, Liberto D, Muzio L. Human papillomavirus: Its identikit and controversial role in oral oncogenesis, premalignant and malignant lesions (Review). Int J Oncology 2007; 30(4):813-23.

12. Fernandes J V, de Medeiros Fernandes TA. Human papillomavirus: biology and pathogenesis. Human papillomavirus and related diseases 2011; 1:3-40.

13. Angiero F, Gatta LB, Seramondi R, Berenzi A, Benetti A, Magistro S, Ordesi $P$, Grigolato $P$, Dessy E. Frequency and role of HPV in the progression of epithelial dysplasia to oral cancer. Anticancer research 2010; 30(9):3435-40.

14. Feller L, Lemmer J . Oral leukoplakia as it relates to HPV infection: a review. Int J Dentistry 2012:1-7.

15. J alouli M M, J alouli J , Hasséus B, Öhman J , Hirsch J M, Sand L. Association of Human Papillomavirus I nfection in Healthy Oral Mucosa, Oral Dysplasia, and Oral Squamous Cell Carcinoma. J Oral Health Dental Management 2015; 14(5):327-33.

16. Kumaraswamy KL, Vidhya M. Human papilloma virus and oral infections: an update. J Can Res Ther 2011; 7(2):120-7.

17. Ha PK, Califano J A. The role of human papillomavirus in oral carcinogenesis. Crit Rev Oral Biol Med 2004; 15(4):18896.

18. Nemes J A, Deli L, Nemes Z, Márton IJ . Expression of p16 INK4A, p53, and $\mathrm{Rb}$ proteins are independent from the presence of human papillomavirus genes in oral squamous cell carcinoma. Oral Surg Oral Med Oral Pathol Oral Radiol Endod 2006 ; 102(3):344-52.

19. Langendijk J A, Psyrri A. The prognostic significance of p16 overexpression in oropharyngeal squamous cell carcinoma: implications for treatment strategies and future clinical studies. Annals of oncology 2010; 21(10):1931-4.

20. Ai L, Stephenson KK, Ling W, Zuo C, Mukunyadzi P, Suen JY, Hanna E, Fan CY. The p16 (CDKN2a/INK4a) tumorsuppressor gene in head and neck squamous cell carcinoma: a promoter methylation and protein expression study in 100 cases. Modern pathology 2003; 16(9):944-50.

21. Romagosa C, Simonetti S, Lopez-Vicente L, Mazo A, Lleonart ME, Castellvi J , y Cajal SR. p16I nk4a overexpression in cancer: a tumor suppressor gene associated with senescence and high-grade tumors. Oncogene 2011; 30(18):2087-97.
22. Patil S, Rao RS, Amrutha N, Sanketh DS. Analysis of human papilloma virus in oral squamous cell carcinoma using p16: An immunohistochemical study. J I nt Soc Prevent Communit Dent 2014; 4(1):61-6.

23. Syrjanen S, Lodi G, von Bultzingslowen I, Aliko A, Arduino P, Campisi G, Challacombe S, Ficarra G, Flaitz C, Zhou HM, Maeda $\mathrm{H}$. Human papillomaviruses in oral carcinoma and oral potentially malignant disorders: a systematic review. Oral Diseases 2011; 17(s1):58-72.

24. Chi AC, Day TA, Neville BW. Oral cavity and oropharyngeal squamous cell carcinoma-an update. CA: A Cancer J ournal for Clinicians 2015; 65(5):401-21.

25. Lewis J S, Chernock RD, Ma XJ , Flanagan J J , Luo Y, Gao G, Wang X, El-M ofty SK. Partial p16 staining in oropharyngeal squamous cell carcinoma: extent and pattern correlate with human papillomavirus RNA status. Modern Pathology 2012; 25(9):1212-20.

26. Azizi SA, NFS NM, Sailan AT, Ajura AJ, Ibrahim N. Expression of P53 and P16 at Tumour I nvasive Front in Oral Squamous Cell Carcinoma. Cosmetol Oro Facial Surg 2016; 2(1):2-5.

27. Hansson BG, Rosenquist $K$, Antonsson A, Hansson BG, Rosenquist K, Antonsson A, Wennerberg J , Schildt EB, Bladström A, Andersson G. Strong association between infection with human papillomavirus and oral and oropharyngeal squamous cell carcinoma: a population-based case-control study in southern Sweden. Acta oto-laryngologica 2005; 125(12):1337-44.

28. Lewis J r J S, Thorstad WL, Chernock RD, Haughey BH, Yip J H, Zhang Q, EI-M ofty SK. p16 positive oropharyngeal squamous cell carcinoma: An entity with a favorable prognosis regardless of tumor HPV status. AmJ Surgl Pathol 2010; 34(8):1-20.

29. Boy S, Rensburg EJ , Engel brecht S, Dreyer L, Heerden M, Heerden W. HPV detection in primary intraoral squamous cell carcinomas-commensal, aetiological agent or contamination? J Oral Pathol Med 2006; 35(2):86-90.

30. Smeets SJ , Hesselink AT, Speel EJ , Haesevoets A, Snijders PJ , Pawlita M, Meijer CJ, Braakhuis BJ, Leemans CR, Brakenhoff RH. A novel algorithm for reliable detection of human papillomavirus in paraffin embedded head and neck cancer specimen. Int J Cancer 2007; 121(11):2465-72.

31. Larsen CG, Gyldenløve M, J ensen DH, Therkildsen MH, Kiss K, Norrild B, Konge L, Von Buchwald C. Correlation between human papillomavirus and p16 overexpression in oropharyngeal tumours: a systematic review. Brit J Cancer 2014; 110(6): 1587-94.

32. Duncan LD, Winkler M, Carlson ER, Heidel RE, Kang E, Webb D. p16 immunohistochemistry can be used to detect human papillomavirus in oral cavity squamous cell carcinoma. J Oral Maxillofacial Surg 2013; 71(8):1367-75.

33. Mazul AL, Rodriguez-Ormaza N, Taylor J M, Desai DD, Brennan P, Anantharaman D, Gheit T, Tommasino M, AbediArdekani B, Olshan AF, Zevallos J P. Prognostic significance of non-HPV16 genotypes in oropharyngeal squamous cell carcinoma. Oral Oncology 2016; 61:98-103.

34. Singhi AD, Westra WH. Comparison of human papillomavirus in situ hybridization and p16 immunohistochemistry in the detection of human papillomavirusassociated head and neck cancer based on a prospectiveclinical experience. Cancer 2010; 116(9):2166-73. 